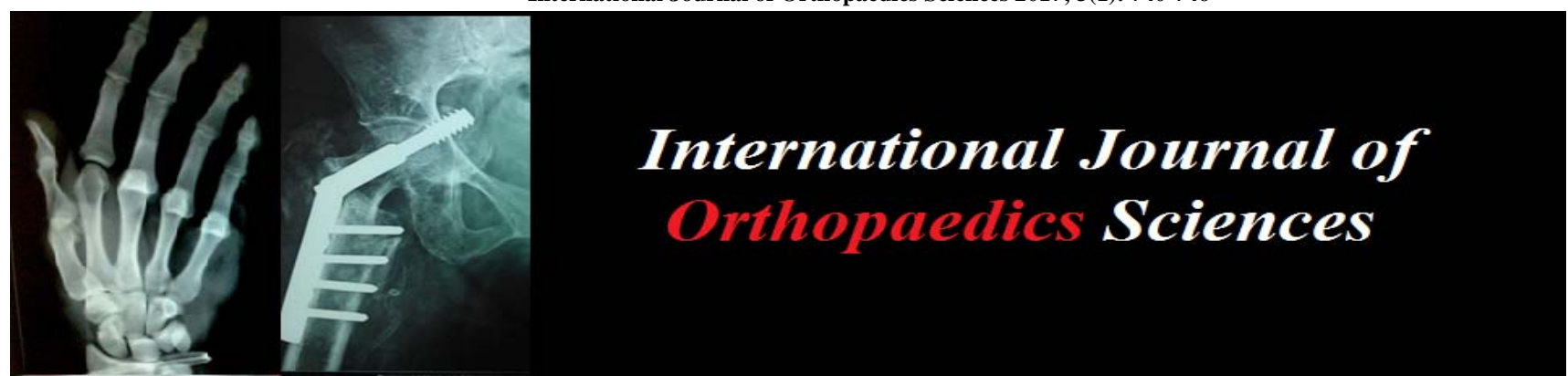

ISSN: 2395-1958

IJOS 2017; 3(1): 740-746

(C) 2017 IJOS

www.orthopaper.com

Received: 19-11-2016

Accepted: 20-12-2016

Dr. Mohammad Asimuddin Assistant Professor, Department of Orthopaedics, KBNIMS Kalaburagi, Karnataka, India

Dr. Marthand Kulkarni Assistant Professor, Department of Orthopaedics, KBNIMS, Kalaburagi, Karnataka, India
Correspondence

Subodh Kumar Pathak

Assistant Professor, Department

of Orthopaedics, KBNIMS,

Kalaburagi, Karnataka, India

\section{A clinical study of minimally invasive percutaneous plate osteosynthesis of proximal tibial fractures using locking compression plate}

\author{
Dr. Mohammad Asimuddin and Dr. Marthand Kulkarni
}

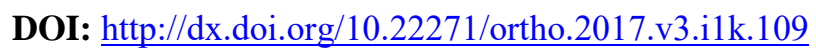

Abstract

Background: Proximal tibia being a prime component of knee joint, which is vital for weight bearing and mobility. Because of its superficial location and vulnerable position, proximal tibia is frequently injured, more frequently in road traffic accidents (RTA).

With the better understanding of fracture healing, recent advances in tissue friendly minimally invasive techniques like MIPPO (Minimally Invasive Percutaneous Plate Osteosynthesis) and development of technically mature implant systems like LCP (Locking Compression Plate), which have shown promising results in the treatment of complex proximal tibial fractures, thus overcoming most of the drawbacks of conventional plating and other treatment modalities. The LCP is an internal fixator system, which is a hybrid of LC-DCP and LISS plate. The LCP can be applied in 3 different ways (1) As compression plate, (2) As combined compression and plating principle, and (3) As pure internal fixator (bridge plate).

Material and Methods: We studied 20 patients involving proximal tibial fractures fixed with LCP using MIPPO technique.

Results: We followed up all the patients for a period ranging from 16-36 weeks. The average time for union of fractures was 19 weeks ranging from 16-24 weeks. An average knee range of motion of 0-121 was achieved. In our study excellent results were achieved in 10 fractures $(47.6 \%)$, good in 8 fractures $(38.1 \%)$, fair in 2 fractures $(9.6 \%)$ while poor result was seen in one fracture $(4.7 \%)$. We had a total of 6 complications which included 2 knee stiffness, 1 post operative loss of reduction, 1 infection, 1 varus deformity and 1 knee instability.

Conclusion: The patient sample approximately reflected the regular trauma patients encountered at our setup. The fractures treated with pure bridge plating and combined principle of compression and bridge plating healed rapidly by secondary fracture union, achieving strong union across the fracture site. In addition by MIPPO technique, there is minimal soft tissue damage and minimal disruption of blood supply to fracture ends, resulting in faster healing and fracture union.

Keywords: Proximal tibial fracture, locking compression plate, bridge plating

\section{Introduction}

The proximal tibia is involved in body weight transmission though the knee joint and leg, it plays a vital role in the knee joint function and stability ${ }^{[1]}$. Fractures of proximal tibia have historically been difficult to treat because of its subcutaneous location of the anteromedial surface of the tibia. Severe bone and soft tissue injuries are not infrequent and there is high incidence of open fractures compared to other long bones ${ }^{[2]}$. The proximal tibial fractures are one of the commonest intra articular fractures, generally these injuries fall into two broad categories, high energy fractures and low energy fractures.

The majority of tibial plateau fractures are secondary to high velocity road traffic accidents and fall from height ${ }^{[3]}$, where fractures result from direct axial compression, usually with a valgus (more common) or varus moment and indirect shear forces ${ }^{[4]}$. Extra-articular fractures of the proximal tibia usually secondary to direct bending forces applied to the metadiaphyseal region of the upper leg. Older patients with osteopenic bone are more likely to sustain depression type fracture because their subchondral bone is less likely to resist axial directed load ${ }^{[5]}$. 
The aim of surgical treatment of proximal tibia fracture is to restore congruent articular surfaces of the tibial condyles, maintaining the mechanical axis and restoring ligamentous stability. Thus eventually can achieve functional painless and good range of motion in the knee joint ${ }^{[1]}$.

With the gradual changes in the treatment modalities of fracture proximal end of tibia from conservative measures like cast bracing, traction, immobilization to surgical intervention for better results. There is a need for better conservative minimal invasive surgery and better fracture fixation technique in view of complications associated with conventional plates screw system, radical exposure of fracture site and inherent fracture and soft tissue injury.

With the better understanding of fracture healing biology and biomechanics of fracture fixation and healing, there is evolution of new concept of fracture fixation with fixed angular stable plate, (internal fixator, LCP) and minimally invasive surgical techniques.

The trend of treatment is towards biological fixation, which can be accomplished by LCP and MIPPO technique.

The conventional plate fixation is based on principle of friction and compression of plate to bone. It needs radical exposure of fracture site adding to devitalization of soft tissue and bone leading to higher incidence of wound healing problem and infections. In addition there is osteoporosis and bone necrosis at bone plate and screw interface leading to infection, toggling of screw, loss of fixation, collapse, malunion and nonunion.

To solve these problems there has been constant research and development in better fixation with minimal tissue damage and devitalization.

Early attempts to attain angular stability with conventional screw and plate by cement fixation of screw in bone, to prevent toggling of screw was followed by fixing the screw to plate by SCHUHLI nuts (threaded washer), development of PC-fix plate, Zespol plate. Less invasive stabilization system was designed for fractures involving ends of bone. There was further research to combine conventional screw slot with locking screw slot in the opposite ends of same hole lead to development of AO (LCP) ${ }^{[6]}$. Further recent changes in designs with options to change axis of screw in polyaxial plate and increase flexibility of construct by far cortex locking screw and dynamic locking screw have evolved.

The new system (LCP) has been regarded as technically mature. It offers numerous fixation possibilities and has proven its worth in complex fracture situation, revisions and osteoporotic bones.

The main objective of the present study was to restore the anatomy of articular surface of upper end of tibia and knee joint by operative treatment with

Internal fixation and to assess the union of fractures after internal fixation and to assess the range of motion of knee joint after surgical treatment.

\section{Materials and Methods}

This study was conducted in the department of orthopaedics at Khaja Bandanawaz Teaching and General Hospital, Kalaburagi for a period of one and half year from jan 2015 to june 2016. The total number of cases studied were 20 with the youngest 22 years and oldest 55 years old.

The aim was to study the treatment of proximal tibial fracture by locking compression plate with minimally invasive percutaneous plate osteosynthesis to obtain stable, pain free mobile knee joint and prevent the development of osteoarthritis.

\section{Inclusion criteria}

Patients with proximal tibial fractures aged 20 years and above.

\section{Exclusion criteria}

- Patients with Gustilo - Anderson Type-3 compound proximal tibial fractures.

- Children with proximal tibial fractures in whom the growth plate is intact.

- Patients with pathological proximal tibial fractures other than osteoporosis.

- Patients managed conservatively for being unfit for surgery.

- Proximal tibial fractures with neurovascular deficits.

Demographic data of patients were recorded on admission and through history and clinical examination was done. The fractures were assessed for soft tissue injuries and followed by radiological assessment of fracture with AO classification.

The following protocol was followed once patient was admitted and planned for surgery. (Figures 1-8)

1. Fracture was stabilized with slab immobilization and limb elevation given.

2. Surgery delayed till favourable healing of soft tissue at operative site.

3. Use of preoperative antibiotic and continued till the removal of suture.

4. Patients were stabilized hemodynamically and physical fitness for surgery was obtained

5. Preoperative planning for length of plate, number of screws and principle of fixation was done.

6. In our study, fractures are reduced with traction on fracture table and fixation was done under c-arm guidance.

We operated all the patients with minimally invasive percutaneous plate osteosynthesis using lateral LCP proximal tibia.

We used anterolateral approach for all patients with 'inverted hockey stick incision'.

The primary difference with the LCP is the method of locking head screw insertion. Here since the locking head of the screw has to get locked in the locking part of the combi hole, the direction of the drilling has to be perfect. Hence drilling for all locking head screws has to be done after fixing drill sleeve to locking portion combi hole of plate. Non locking regular screws whenever used were inserted prior to insertion of the locking screws. As per routine protocol care was given to the general condition, fluid balance, IV antibiotics and analgesics so as to mobilize patients earlier.

\section{Mobilization}

Based on the type of fracture and quality of fixation, the decision regarding continuation of external splint with plaster of paris slab was made and patients was advised static quadriceps exercises. Fractures with stable fixation were mobilized after removal of drain. Patients were encouraged for flexion to achieve full range of motion of knee joint to achieve $90^{\circ}$ flexion at the end of 2 weeks after surgery. Continuous passive motion exercise was used in patients with stiffness. Partial weight bearing was delayed until 6 weeks and full weight bearing allowed after 12-16 weeks. Patients were regularly followed up at 6-8 weeks interval till complete fracture union. 


\section{During follow-up}

1. The course of fracture healing was documented radio logically with a minimum of 6 weeks interval. The moment of complete healing was defined as radio logically complete bone regeneration at fracture site.

2. Evaluation of any possible loss of reduction

3. Assessment and analysis of any complication

The duration of patients follow-up ranged from 16 weeks to 36 weeks. (Fig -9)

\section{Fracture classification}

The AO classification of proximal tibial fractures ${ }^{[7]}$

Type A : Metaphyseal fractures that do not involve the joint surface.

$\begin{array}{lll}\text { A1 } & : & \text { Avulsion Fracture } \\ \text { A2 } & : & \text { Metaphyseal Simple Fracture } \\ \text { A3 } & : & \text { Metaphyseal Multifragmentary Fracture } \\ \text { Type B } & : & \text { Partial articular fracture } \\ \text { B1 } & : & \text { Partial articular, pure split } \\ \text { B2 } & : & \text { Partial articular fracture, pure depression } \\ \text { B3 } & : & \text { Partial articular fracture, split depression } \\ \text { Type C } & : & \text { Complete articular fractures } \\ \text { C1 } & \text { Complete articular fracture, articular simple, } \\ \text { metaphyseal simple } & \text { Complete articular fracture, articular simple, } \\ \text { C2 : articular } \\ \text { metaphyseal multifragmentary fracture, } \\ \text { C3 : Complete } \\ \text { multifragmentary }\end{array}$

\section{Observation and Results}

In our study 20 patients with 21 proximal tibial fractures were treated with LCP using MIPPO technique. One patient was having bilateral proximal tibia fracture. Most of the patients belongs to 20-50 years of age group, who are more prone for RTA.

Most of our patients were male. It reflected the general population which visit our both outpatient as well as the emergency trauma section.

The majority of proximal tibial fractures in our study were seen in people with high level of activity, who indulge themselves in traveling, because majority of morbidity is due to RTA.

In our study there is a slight right sided predominance compared to the left side.

In our study majority of the fractures were found to be of type $41 \mathrm{~A} 2,41 \mathrm{~A} 3,41 \mathrm{C} 1,41 \mathrm{C} 3$ and type-42 of AO classification which are usually associated with high velocity RTA.

We operated all the fractures in our study with MIPPO technique which caused less tissue dissection and disturbance to fracture site biology. There was less pain and good fracture union. MIPPO demands more surgical skills and we found as the study progressed that the operative time needed for MIPPO technique decreased as we matured more in this technique.

As we operated all fractures in our series with MIPPO technique we used only bridging and combined principles of fixation. We used bridging type of fixation for 16 patient with fracture extending into metaphyseal region and lack of purchase of the screw due to comminution in metaphyseal region. Combined type of principle was used in 5 patients. Here articular reconstruction was essential by compression principle and metaphyseal comminution needed protection from collapse in postoperative period by bridging principle.

We had no cases of any purely implant related complication like screw loosening screw breakage, plate failure. Complications occurred in 6 fractures.
- Average time for union of fracture was 19 weeks (range from 16-24 weeks).

- One patient with knee joint stiffness is due to associated with ipsilateral inter condylar fracture of femur. Another patient with knee joint stiffness is due to lack of postoperative mobilization.

- One patient with knee instability due to associated anterior cruciate ligament injury.

- One patient developed deep infection of operative site. Plate was removed and treated with antibiotic and above knee pop cast applied, later fracture united at 24 weeks.

- One patient developed varus deformity due to collapse of medial condyle post operatively.

- In one patient medial condyle collapse occurred in postoperative period due to toggling of cancellous screw applied to condyles.

In our study 3 patients were having associated injuries.

One patient was having fracture midshaft femur which was treated with intramedullary interlocking nail. Another patient was having fracture midshaft humerus and fracture midshaft femur which were treated with CRIF with intramedullary interlocking nail for humerus and femur respectively. Another patient was having associated compound Gustilo-Anderson type-2 comminuted supracondylar with intercondylar fracture lower end femur which was treated with external fixator.

Clinical evaluation was carried out using the modified Rasmussen clinical criteria ${ }^{[8]}$ the clinical evaluation depends on pain, walking capacity, knee extension, and range of motion, stability, and power of quadriceps muscles.

$\begin{array}{ll}\text { Modified Rasmussen criteria for clinical assessment } & { }^{[8]} \\ \text { Pain } & \text { Points } \\ \text { None } & 6 \\ \text { Occasional } & 5 \\ \text { Stabbing pain in certain positions } & 3 \\ \text { Constant pain after activity } & 1 \\ \text { Significant rest pain } & -3\end{array}$

\section{Walking capacity}

Normal walking capacity for age 6

Walking outdoors $(>1 \mathrm{~h}) \quad 5$

Walking outdoors $(15 \mathrm{~min}-1 \mathrm{~h}) \quad 3$

Walking outdoors $(<15 \mathrm{~min}) \quad 1$

Walking indoors only

Wheelchair/bedridden

\section{Knee extension}

Normal

Lack of extension $\left(<10^{\circ}\right)$

Lack of extension $\left(>10^{\circ}\right)$

Lack of extension $\left(>20^{\circ}\right)$

4

2

0

\section{Total range of motion}

Full

6

At least $120^{\circ}$

At least $90^{\circ}$

At least $60^{\circ}$

$<60^{\circ}$

\section{Stability}

Normal stability in extension and $20^{\circ}$ flexion 6

Abnormal stability in $20^{\circ}$ flexion 4

Instability in extension $\left(<10^{\circ}\right) \quad 2$

Instability in extension $\left(>10^{\circ}\right)$ 


\section{Power of quadriceps}

\section{Grade 5}

Grade 3-4

Grade $<3$

1

\section{Maximum score}

Excellent

Good

Fair

Poor

$20-23$

$<20$

In our study, out of 21 fractures treated, 10 fractures gave excellent result, 8 fractures healed with good results, 2 fractures with fair results and in 1 case the result was poor. (Table-1)

Table 1: Clinical results

\begin{tabular}{|c|c|c|}
\hline Clinical results & Number of fractures & Percentage \\
\hline Excellent & 10 & 47.6 \\
\hline Good & 8 & 38.1 \\
\hline Fair & 2 & 9.6 \\
\hline Poor & 1 & 4.7 \\
\hline Total & 21 & 100 \\
\hline
\end{tabular}

\section{MIPPO Technique}

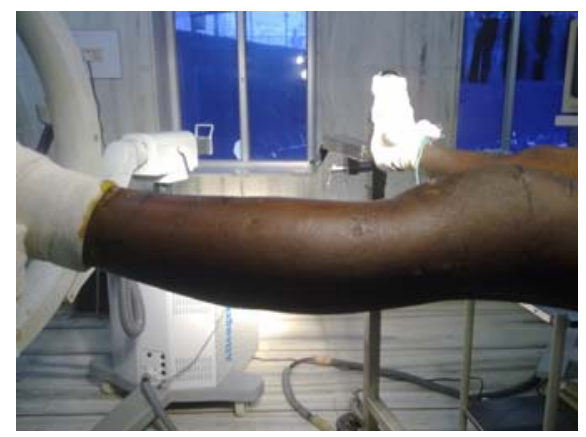

Fig 1: Fracture reduced by traction on fracture table

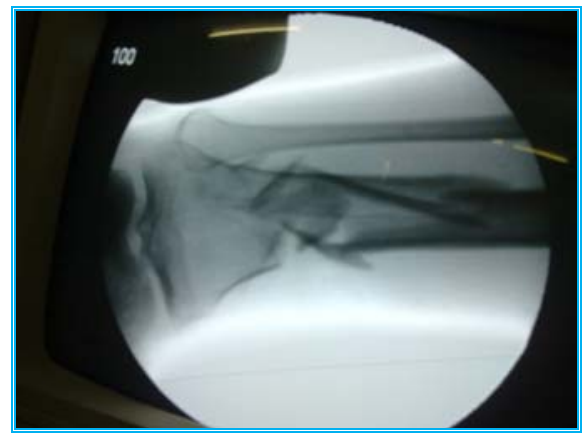

Fig 2: Fracture reduction with traction confirmed under C-arm

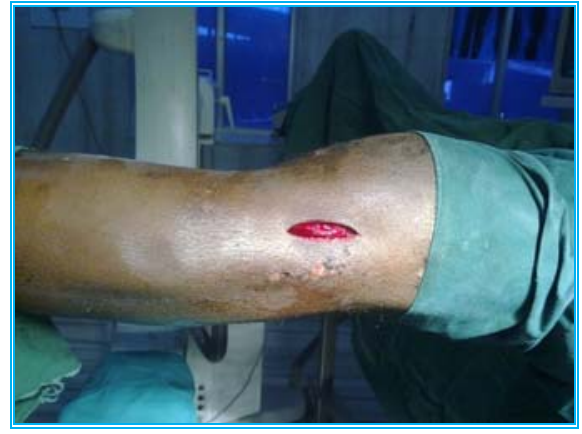

Fig 3: Painting, draping and incision

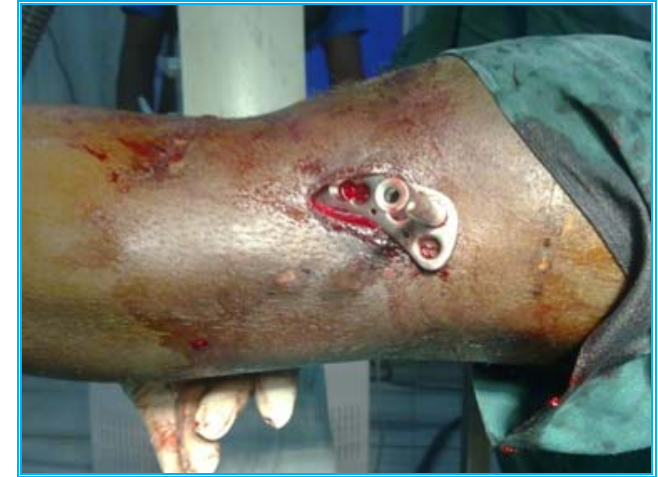

Fig 4: Plate is inserted in sub-muscular plane with minimal incision away from fracture site

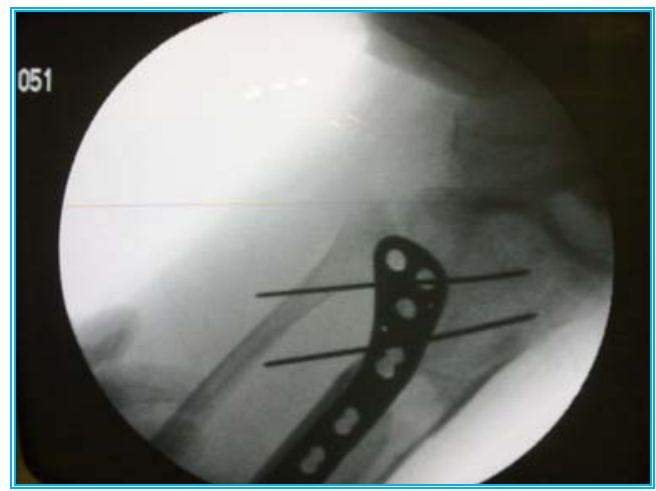

Fig 5: Proper placement of plate confirmed with C-Arm and maintained with K-wire

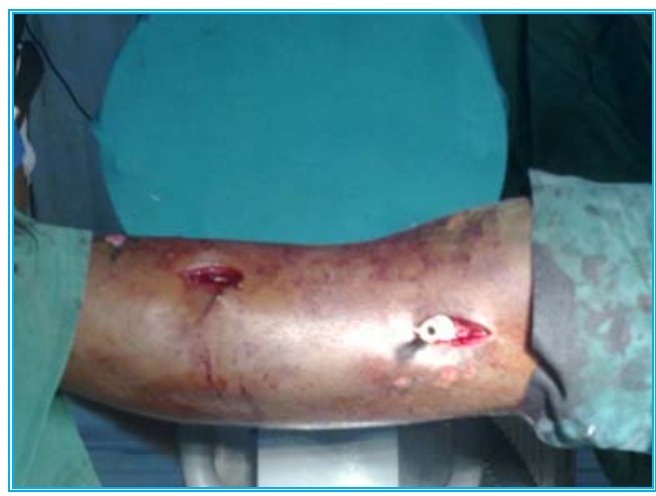

Fig 6: Fixed angle drill sleeve applied to the locking slot of plate to drill for insertion of locking screw

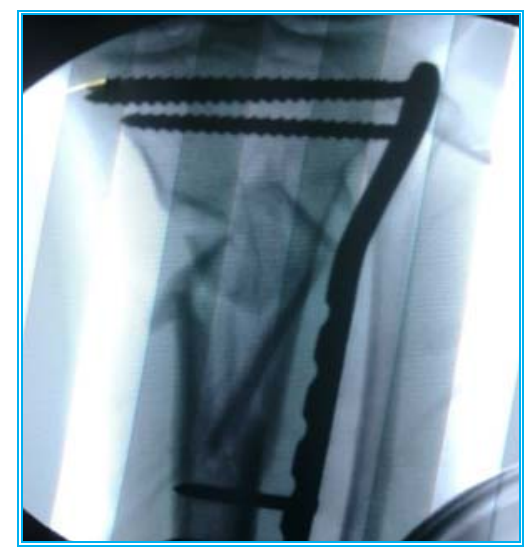

Fig 7: LCP fixed with bridging principle to tibial condyle and shaft with locking screws (C-arm AP view) 


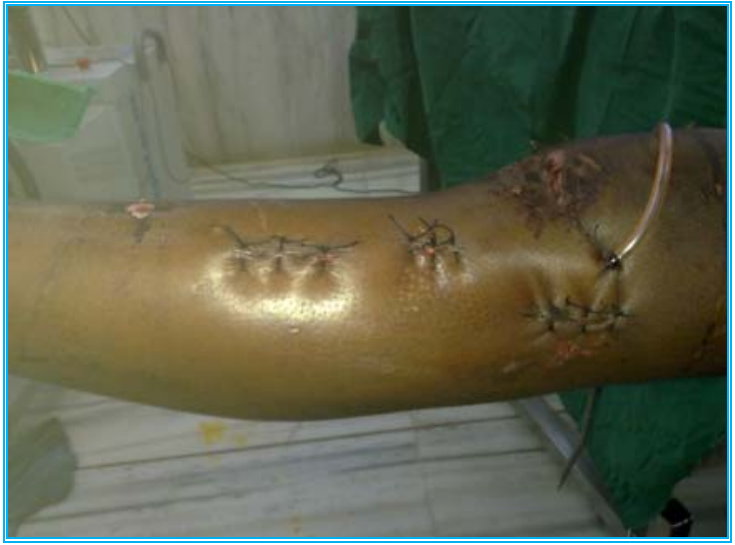

Fig 8: Closure
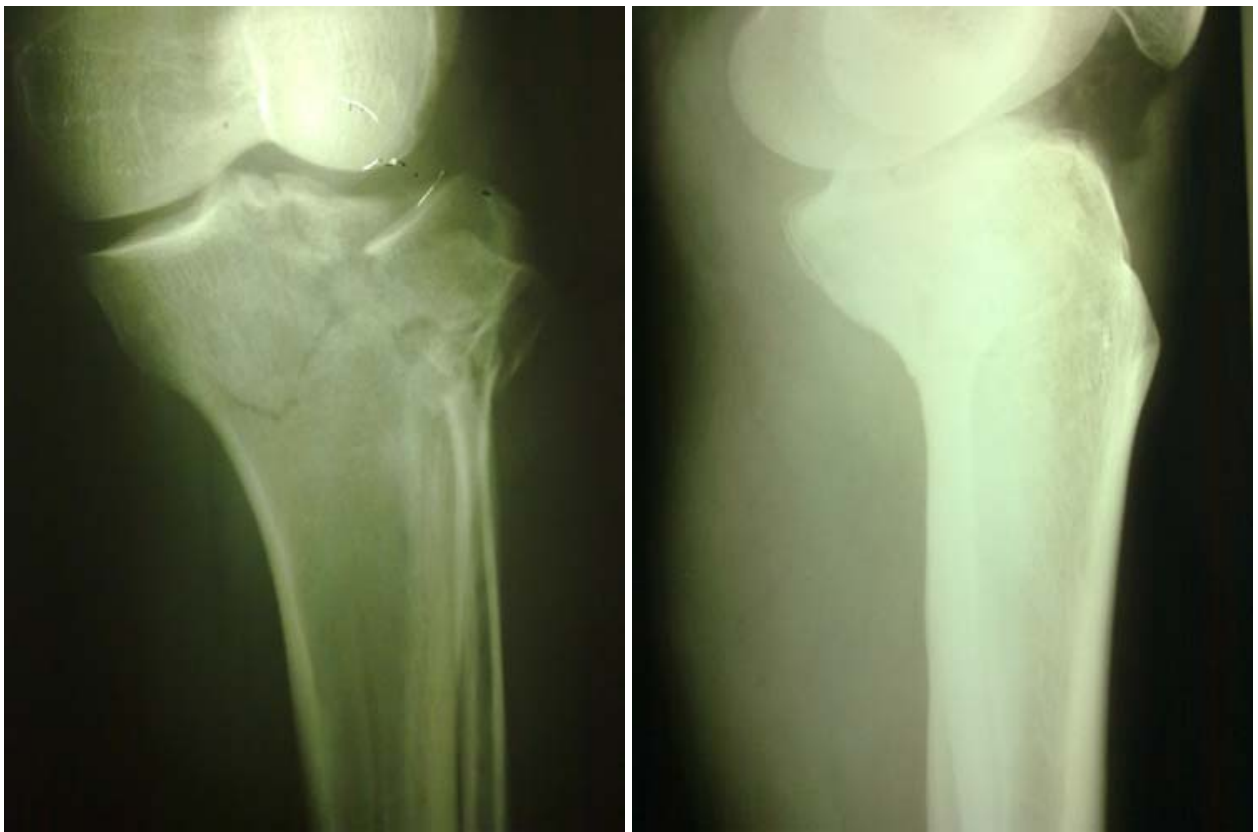

Fig 9: Clinical x-rays

\section{Discussion}

The incidence of proximal tibial fractures has not only increased with increase in RTA but also the complexity of fracture has changed due to high velocity direct impact causing more of comminution at fracture site.

Any fracture around the weight bearing joint like knee joint is of paramount importance as these would result in significant morbidity and compromised quality of life. Treatment modalities have been continuously changing in quest of better results.

Hence orthopaedic surgeons have to encounter the challenges posed in the treatment of complex proximal tibial fractures more frequent in the coming days.

Of late with the better understanding of peculiarities in proximal tibial fracture, fracture healing, and complications associated with them. There has been research in better tissue friendly approaches(MIPPO) and development of better technically mature implant systems (LCP) for fracture fixation, which are showing promising results by early restoration of strength at bone fracture site and function of knee joint.

We present the clinical study of minimally invasive percutaneous plate osteosynthesis of 21 proximal tibial fractures with lateral locking compression plate. The analysis of the results were made in terms of age of patients, sex distribution, occupation of patients, laterality of fracture, mode of injury, analysis of the type of fracture, principle of LCP fixation, fracture union, range of motion and complications. The patients with fracture in our study occurred between the age of 20 to 60 years with maximum incidence being involving the productive age group of $20-50$ years (90\%). P.A Cole et al [9] in 2004 also found the majority of patients in productive age and average of 45 years, Correlated well with the study of Ricci ${ }^{[10]}$ and Stannard ${ }^{[11]}$ with average of 53 years and 38 years respectively.

In our study majority of the patients were males $95 \%$, which can be attributed to our Indian setup where the female population largely work indoor and do not travel much.

Occupationally proximal tibial fractures were seen in people with high level of activity, movement and travel.

In our study the commonest mode of injury was road traffic accident (85\%) the other being assault $(15 \%)$. There was not much difference in the laterality of the fracture. The right tibia was affected in $55 \%$, left tibia in $40 \%$ of cases and bilateral in $5 \%$ of cases.

In our study we studied 21 fractures out of which most of the fractures fall into type $41 \mathrm{~A} 2, \mathrm{~A} 3, \mathrm{C} 1, \mathrm{C} 3$ and type-42 of AO classification of proximal tibial fractures. Different authors used different criteria for the surgical management of these 
fractures. P.A. Cole et al ${ }^{[9]}$ treated 44 proximal tibial fractures with locking compression plate and enrolled patient with type41 A2, A3, C1, C2, C3 and proximal type-42 of AO classification.

In our study we operated all the patients with minimally invasive percutaneous plate osteosynthesis using lateral locking compression plate for proximal tibia. By this there was less of tissue dissection and decreased postoperative pain which helped us to mobilize the knee joint earlier and avoid knee joint stiffness.

In our study we used combined principle of fixation in 5 patients $(24 \%)$ and achieved good articular reconstruction. We used bridging type of principle in 16 patients (76\%). In metaphyseal fracture comminution and osteoporosis, there was the risk of collapse. In these patients as LCP implant system provided good fixation, which prevents collapse of fracture during postoperative period.

In our study we approached all the fractures with anterolateral incision using MIPPO technique, thus avoiding subcutaneous medial approach or dual approach.

The average time for union of fractures was 19 weeks in our study, ranging from 16 to 24 weeks.

An average of $121^{\circ}$ knee joint range of motion was achieved. Soft tissue damage, intraarticular fracture, severity of fracture, treatment option and physiotherapy determined knee range of motion. Both P.A Cole et al ${ }^{[9]}$ and Egol et al ${ }^{[12]}$ reported similar range of movement results when using locked plate for these fractures (range 0 to $122^{\circ}$ and 0 to $109^{\circ}$ respectively).

In our study one patient develop knee stiffness due to associated ipsilateral fracture of femoral condyle treated with physiotherapy and regain $70^{\circ}$ of flexion another patient present with knee joint stiffness at end of 6 months of Postoperative period he was treated with physiotherapy and he regained a range of movement from complete extension to $90^{\circ}$ of flexion. In our study one patient develop deep infection by $7^{\text {th }}$ postoperative day secondary to uncontrolled diabetes and skin infection in thigh region, he was treated with IV antibiotics (ceftriaxone and amikacin), implant removal and above knee POP cast application, subsequently infection was controlled and fracture union occurred at the end of 24 weeks postoperatively. This was at the rate of $4.7 \%$. These findings are comparable with the studies conducted by Egol et al [12] who reported no infection, Stannard et al ${ }^{[11]}$ reported $5.9 \%$ rate of infection and P.A Cole et al ${ }^{[9]}$ with $4 \%$ rate of infection.

In our study one patient developed loss of reduction with collapse of medial condyle at the end of 08 weeks of postoperative period treated with above knee POP cast for 12 weeks subsequently fracture united with minimal depression of medial condyle.

Another patient developed varus deformity due to collapse of medial condyle at 09 weeks of postoperative period due to early weight bearing he was treated with application of above knee pop cast for 2 weeks and adviced to wear knee brace while walking. The mal-alignment rate was $4.7 \%$ in our series, as compared to $2.6 \%$ in a study by P.A Cole et al ${ }^{[9]}$ and $22 \%$ in the study by Phistikul et al ${ }^{[13]}$ series.

In our study one patient had associated anterior cruciate ligament injury and was treated with above knee pop cast till fracture unite and to wear knee support while walking and to undergo ACL repair in subsequent days.

The period of immobilization was individualized depending on strength of fracture fixation. The benefits of early knee motion include reduced knee joint stiffness and improved cartilage healing (regeneration) and promoted good callus formation and remodelling.

Thus in our study we achieved $100 \%$ fracture union at an average of 19 weeks with an average knee range of motion between 0 to $121^{\circ}$ with an acceptable rate of infection of $4.7 \%$ and malunion of $4.7 \%$. These results are comparable with other documented standard series of Ricci et al ${ }^{[10]}$ (2004), P.A Cole et al ${ }^{[9]}$ (2004), Stannard et al ${ }^{[11]}$ (2004) and Egol et al ${ }^{[12]}$ (2004), wherein high union rates, greater knee joint range of motion, good alignment and fewer complications were noted.

\section{Conclusion}

At the end of our study, the following conclusion could be drawn from the minimally invasive percutaneous plate osteosynthesis of proximal tibial fracture using locking compression plate:

- There is an increase in the complexity of proximal tibial fractures with increasing road traffic accident.

- As most of the patients sustained these fractures belong to physically highly active and productive age group, they need optimal treatment to get back to their previous work capacity and avoid long term complications like osteoarthritis.

- These fractures with inherent less soft tissue coverage and added soft tissue trauma poses higher risk of postoperative wound dehiscence and infection. Hence they demand tissue friendly less invasive procedure (MIPPO) after giving adequate time for soft tissue injury and edema to heal.

- The anchorage of the locking head screw was found to be excellent even in osteoporotic bone. Drilling the holes for the locking head screw should always be through a drill bit in fixed angle drill sleeve.

- While bridging a fracture, care must be taken to select a strong plate of adequate length and leave at least 2 to 3 plate hole without inserting screws in the fracture site. This prevents the stress concentration and achieves an elastic fixation which is essential for secondary fracture union.

- Even in patients with extensive metaphyseal comminuted fracture, LCP internal fixator system acts as a single implant (fixed angle construct) and prevents collapse of fracture fragments postoperatively and subsequently bone deficit will heal with callus formation.

- When LCP is used as combined principle of fixation, we can reconstruct tibial plateau with compression and prevent it from collapse by bridging principle.

- We treated all the fracture in our study with MIPPO technique and found a rapid healing by secondary fracture union and hence achieving strong bone union across the fracture site due to inherent benefits of less tissue damage and minimal disturbance of fracture site biology.

Thus we conclude that the locking compression plate system with its various options of fixation acts as a good biological fixation even for difficult fracture situations with added benefits of using LCP system by MIPPO technique. But this also involves the complication that may occur unless properly planned preoperatively and follow guided principles intraoperatively.

\section{References}

1. Kenneth Egol A, Kenneth Koval J. In: Fracture of proximal tibia: chapter 50, Rockwood and Green's Fracture in Adults, $6^{\text {th }}$ edition, Lippincott Williams and Wilkins. 1999, 2. 
2. Charles M. Court-Brown, In: Fracture of tibia and fibula. Chapter 52, Rockwood and Green's "Fracture in Adults, $6^{\text {th }}$ edition, Lippincott Williams and Wilkins, 2080, 2.

3. Schulak DJ, Gunn DR. Fracture of the tibial plateaus. Clin Orthop, 1975; 109:166-177.

4. Koval KJ, Hulfut DL. Tibial plateau fracture: evaluation and treatment. J Am Acad Orthop Surg. 1995; 3(2):86-94.

5. Biyani A, Reddy NS, Chaudhary et al. The results of surgical management of displaced tibial plateau fracture in the elderly. Injury. 1995; 26(5):291-297.

6. Stoffel Dietaru K. Biomechanical testing of the LCP how can stability in locked internal fixator be controlled? Injury. 2003; 34(2):B11-9.

7. Muller M. The comprehensive classification of long bones. In: Muller ME, Allgower M, Schneider R, Willenegger $\mathrm{H}$, eds. Manual of internal fixation. Berlin: Springer- Verlag, 1995, 118-158.

8. Rasmussen PS. Tibial condylar fractures:impairment of joint stability as an indication for surgical treatment. J Bone Joint Surg Am. 1973; 55:1331-50.

9. Cole PA, Zlowodzki M, Kergor J. Treatment of proximal tibia fracture using the Less Invasive Stabilization System. Surgical experience and early clinical results in 77 fractures. J Orthop. 2004; 18:528-535.

10. Ricci WM, Rudzki JR, Borrelli J Jr. Treatment of complex proximal tibial fracture with the less invasive skeletal stabilization system. J Orthop Trauma, 2004; 18:521-527.

11. Stannard JP, Wilson TC, Volgas DA, Alonso JE. Fracture stabilization of proximal tibial fracture with the proximal LISS: early experience in Birmingham, Alabama (USA). Injury. 2003; 34:A30-35.

12. Egol KA, Su E, Tejwani NC, Sims SH, Kummer FJ, Koval KJ. Treamtent of complex tibial plateau fractures using the less invasive stabilization system plate. J trauma. 2004; 57:340-46.

13. Phistikul, Mikinley, Nepola. Complications of locking plate fixation in complex proximal tibia injuries. J Orthop Trauma. 2007; 21:83-91. 